\title{
SISTEMATIZAÇÃO DA ASSISTÊNCIA DE ENFERMAGEM E A SEGURANÇA DO PACIENTE NO AMBIENTE DOMICILIAR
}

Fernanda Bernardo dos Santos ${ }^{1}$

Geilsa Soraia Cavalcanti Valente ${ }^{1}$
ORCID: https://orcid.org/0000-0001-5461-8621

ORCID: http://orcid.org/0000-0003-4488-4912

Objetivo: Identificar os tipos de riscos relacionados à segurança que os pacientes acamados estão mais expostos em seu domicílio e descrever as dificuldades que a equipe multidisciplinar de Atenção Básica encontra para proporcionar a segurança do paciente acamado de forma efetiva em seu domicilio. Método: Trata-se de um estudo qualitativo, descritivo, exploratório, do tipo pesquisa-convergente-assistencial. Foram considerados como critérios de inclusão os profissionais que aceitaram participar da pesquisa e que exercem cuidados direcionados ao paciente. Os critérios de exclusão adotados, foram: profissionais que estiveram afastados por qualquer motivo durante a coleta de dados. $\mathrm{Na}$ coleta de dados foi utilizada uma oficina de Educação Permanente. Resultados: Confecção do instrumento de registro, com base na Classificação Internacional Para a Prática de Enfermagem (CIPE) e nas recomendações para anotações de enfermagem do Conselho Federal de Enfermagem (Cofen). Conclusão: Foram identificados como principais riscos à segurança do paciente acamado no ambiente domiciliar: Falta de apoio familiar; Adesão ao regime medicamentoso; Reação medicamentosa; Risco de infecção; Capacidade de executar a higiene prejudicada: Risco de queda. Os profissionais de saúde devem estar capacitados para desenvolver ações de promoção, prevenção, proteção e reabilitação da saúde, no âmbito individual e coletivo.

Descritores: Segurança do Paciente; Atenção Básica à Saúde; Processos de Enfermagem.

\section{SYSTEMATIZATION OF NURSING CARE AND PATIENT SAFETY IN THE HOME ENVIRONMENT}

Objective: To identify the types of safety-related risks that bedridden patients are most exposed to at home, and to describe the difficulties that the multidisciplinary Primary Care team encounters in providing effective bedridden patient safety at home. Method: This is a qualitative, descriptive, exploratory, research-convergent-care study. Inclusion criteria were professionals who agreed to participate in the research and who exercise patient-oriented care. Exclusion criteria were: professionals who were away for any reason during data collection. In the data collection a permanent education workshop was used. Results: Making the registration instrument, based on the International Classification for Nursing Practice (CIPE) and the recommendations for nursing notes of the Federal Council of Nursing (COFEN). Conclusion: The main risks to the safety of bedridden patients in the home environment were: Lack of family support; Adherence to the drug regimen; Drug reaction; Risk of infection; Ability to carry out impaired hygiene; Risk of falling. Health professionals should be able to develop health promotion, prevention, protection and rehabilitation actions, both individually and collectively.

Descriptors: Patient Safety; Primary Health Care; Nursing Processes.

\section{SISTEMATIZACIÓN DE LAASISTENCIA DE ENFERMERÍA Y LA SEGURIDAD DEL PACIENTE EN EL AMBIENTE DOMICILIAR}

Objetivos: Identificar los tipos de riesgos relacionados con la seguridad a los que los pacientes encamados están más expuestos en el hogar y describir las dificultades que el equipo multidisciplinario de Atención Primaria encuentra para brindar seguridad efectiva al paciente encamado en el hogar. Metodo: Este es un estudio cualitativo, descriptivo, exploratorio, de investigación-atención convergente. Los criterios de inclusión fueron profesionales que aceptaron participar en la investigación y que ejercen una atención orientada al paciente. Los criterios de exclusión fueron: profesionales que estuvieron fuera por cualquier motivo durante la recolección de datos. En la recolección de datos se utilizó un taller de educación permanente. Resultados: Realización del instrumento de registro, basado en la Clasificación Internacional para la Práctica de Enfermería (CIPE) y las recomendaciones para notas de enfermería del Consejo Federal de Enfermería (COFEN). Conclusión: Los principales riesgos para la seguridad de los pacientes encamados en el hogar se identificaron como: falta de apoyo familiar; Adherencia al régimen de drogas; Reacción a los medicamentos; Riesgo de infección; Capacidad para llevar a cabo una higiene deteriorada; Riesgo de caídas. Los profesionales de la salud deberian poder desarrollar acciones de promoción, prevención, protección y rehabilitación de la salud, tanto individual como colectivamente.

Descriptores: Seguridad del Paciente; Atención Primaria de Salud; Procesos de Enfermería.

IUniversidade Federal Fluminense

Autor correspondente: Fernanda Bernardo dos Santos E-mail: nanndabernardo@hotmail.com

Recebido: $21 / 09 / 2019$

Aceito: 10/12/2019 


\section{INTRODUÇÃO}

O Ministério da Saúde (MS), em 2013, lançou o Programa Nacional de Segurança do Paciente (PNSP), por meio das Portarias GM/MS no 529/2013, com o objetivo de contribuir para a qualificação do cuidado em saúde em todos os estabelecimentos de saúde do território nacional ${ }^{(1)}$. A Segurança do Paciente é um componente essencial da qualidade do cuidado, e tem adquirido, em todo o mundo, importância cada vez maior para os pacientes e suas famílias, para os gestores e profissionais de saúde no sentido de oferecer uma assistência segura. Os incidentes associados ao cuidado de saúde e, em particular, os eventos adversos (incidentes com danos ao paciente), representam uma elevada morbidade e mortalidade em todos os sistemas de saúde. As ações do PNSP devem se articular às demais políticas de saúde com o objetivo geral de integrar e somar esforços aos cuidados em redes de atenção à saúde ${ }^{(2)}$

A Resolução de Diretoria Colegiada (RDC) Agência Nacional de Vigilância Sanitária (ANVISA) no 36/2013 institui ações para a segurança do paciente em serviços de saúde e dá outras providências. Essa normativa regulamenta e coloca pontos básicos para a segurança do paciente como Núcleos de Segurança do Paciente, a obrigatoriedade da Notificação dos eventos adversos e a elaboração do Plano de Segurança do Paciente ${ }^{(3)}$. Neste contexto, insere-se a adoção de medidas sistematizadoras de ações de cuidado, que venham a contribuir com a segurança do paciente e, portanto, privilegiase como objeto de estudo: a Sistematização da Assistência de Enfermagem como uma estratégia de cuidado do paciente acamado no ambiente domiciliar. De acordo com Ministério da Saúde (2011) (4) a Atenção Domiciliar foi instituída no âmbito do SUS pela Portaria no 2.029, de 24 de agosto de 2011, que foi substituída com o apoio do Ministério da Saúde pela Portaria no 2.527, de 27 de outubro 2011, sendo revogada pela portaria GM/MS no 963, de 27 de maio de 2013 (BRASIL, 2013) ${ }^{(5)}$.

Segundo dados do Ministério da Saúde, para os próximos trinta anos, não somente no Brasil, mas no mundo, a população de pessoas idosas triplicará. Nesse contexto, associados ao processo natural do envelhecimento, haverá mais pessoas vivendo com mais de sessenta anos, e, concomitantemente, teremos mais pessoas portadoras de doenças crônicodegenerativas. Assim, vislumbrando esta possibilidade de ampliação de ocupação dos leitos hospitalares, foi desenvolvido o Programa de Atenção Domiciliar ao Idoso PADI (BRASIL, 2011) ${ }^{(4)}$.

Segundo a Prefeitura do Estado do Rio de Janeiro $(2010)^{(6)}$, o PADI foi um projeto criado, em agosto de 2010, pela Secretaria Especial de Envelhecimento Saudável e Qualidade de Vida (SESOV), tendo como objetivo oferecer cobertura a pacientes idosos com possibilidade de tratamento domiciliar em toda a Zona Oeste da Cidade do Rio de Janeiro.
Este serviço, o PADI, oferece assistência prioritariamente a pessoas a partir dos sessenta anos de idade portadoras de doenças crônico-degenerativas tais como: Hipertensão Arterial Severa (HAS), Diabetes Mellitus (DM), pacientes que tenham sofrido Acidente Vascular Encefálico (AVE) isquêmico ou hemorrágico, mas que tenham condições de serem tratadas e acompanhadas no domicílio, em que seja viável o atendimento domiciliar.

A Sistematização da Assistência de Enfermagem (SAE), segundo Silva, Oliveira, Neves e Guimarães ${ }^{(7)}$, pode ser conceituada como um método de prestação de cuidados para a obtenção de resultados relevantes na implementação da assistência, com o objetivo de minimizar as complicações durante o tratamento, de forma a facilitar a recuperação do paciente.

O processo de enfermagem enquanto método consiste em cinco fases: a) Histórico de enfermagem, b) Diagnóstico de enfermagem, c) Planejamento assistencial, d) Prescrição de enfermagem, e) Implementação de enfermagem e f) Avaliação de enfermagem ${ }^{(8)}$

Objetivos: Identificar os tipos de riscos relacionados à segurança que os pacientes acamados estão mais expostos em seu domicilio; Descrever as dificuldades que a equipe multidisciplinar de Atenção Básica encontra para proporcionar a segurança do paciente acamado de forma efetiva em seu domicílio.

\section{METODOLOGIA}

\section{Tipo de estudo}

Trata-se de um estudo qualitativo, descritivo, exploratório, do tipo pesquisa-convergente-assistencial, desenvolvido no Mestrado Profissional em Ensino na Saúde: formação Interdisciplinar para o SUS, da Escola de Enfermagem da Universidade Federal Fluminense - UFF, em convênio com o Conselho Federal de Enfermagem Cofen.

\section{Participantes da pesquisa}

Os participantes da pesquisa foram: 1 enfermeiro, 6 agentes comunitários, 2 técnicos de enfermagem e 1 técnico de higiene bucal, atuantes na clínica da família, tendo em vista que são estes profissionais que prestam o atendimento domiciliar aos pacientes acamados. Foram considerados critérios de inclusão: os profissionais que aceitaram participar da pesquisa e os profissionais que exercem cuidados direcionados ao paciente, que quiseram contribuir para o ensino e para a pesquisa, de modo a melhorar a qualidade da assistência ao paciente. Os critérios de exclusão adotados, foram: profissionais que estiveram afastados por qualquer motivo durante a coleta de dados. 


\section{Local do estudo}

O cenário escolhido para a coleta de dados foi uma unidade da Clínica da Família, localizada na região metropolitana do Rio de Janeiro. A Clínica da Família, onde parte do estudo foi desenvolvido, conta com seis equipes de saúde da família, composta por 1 médico, 1 enfermeiro, 1 técnico de enfermagem e 6 agentes comunitários. A unidade conta com, aproximadamente, 3.200 pessoas cadastradas. Oferece de atendimento domiciliar visita dos profissionais de saúde, como: Médico, Enfermeiro, Técnico de Enfermagem, Agente Comunitário de Saúde e acompanhamento do NASF (Núcleo de Apoio à Saúde da Família), com orientações sobre o cuidados de saúde e autocuidado aos pacientes e familiares.

\section{Coleta de dados}

$\mathrm{Na}$ coleta de dados foi utilizada uma oficina de Educação Permanente. Para este fim, foi tomado como ponto de partida uma pergunta geradora no intuito de saber quais são as dificuldades encontradas pela equipe em relação a segurança do paciente acamado no domicílio. A seguir, foi formulada uma situação problema pelo grupo, com auxílio da pesquisadora; posteriormente, realizou-se um debate, no sentido de identificar os riscos à segurança do paciente e as dificuldades encontradas. As respostas foram gravadas na íntegra.

A partir de então, foi elaborado um mapa conceitual com as principais dificuldades apresentadas pelos participantes, e posterior articulação com os riscos mencionados. Com isto, foram traçados os aspectos relacionados à SAE para a segurança do paciente acamado no domicílio. Estes passos foram realizados pelo próprio grupo, com a coordenação da pesquisadora, conforme os critérios de Wanda Horta, que valoriza as necessidades Psicobiológicas, Psicossociais e Psicoespirituais ${ }^{(9)}$. De acordo com essa tríade de Horta, foram selecionados os diagnósticos de enfermagem da CIPE relacionados com as necessidades humanas básicas e com a segurança do paciente:

Fase de Perscrutação dos Dados: caracterizada pelas estratégias de refinamento de obtenção dos dados através de um grupo focal, onde os atores da prática da visita domiciliar estavam presentes, trazendo suas vivências no domicilio, as dificuldades de adesão ao serviço de saúde por parte do paciente/ e ou familiares, entendimento das orientações sobre o tratamento no domicílio e aderência ao mesmo.

\section{Procedimento de Análise dos Dados}

Os depoimentos resultantes da oficina de Educação Permanente e do grupo focal foram transcritos na íntegra para a realização da análise. A partir de então, foi elaborado um mapa conceitual com as principais dificuldades apresentadas pelos participantes, e posterior articulação com os riscos mencionados.

\section{Procedimentos Éticos}

Atende os preceitos da Resolução n으 466/2012 do Conselho Nacional de Saúde ${ }^{(10)}$, e se baseia nas Normas de Pesquisa em Seres Humanos, com a aprovação do Comitê de Ética em Pesquisa da Faculdade de Medicina do Hospital Universitário Antônio Pedro, de número 2.770 .360 e assegurado o anonimato dos participantes por meio da sua assinatura no Termo de Consentimento Livre e Esclarecido TCLE.

\section{RESULTADOS}

As categorias de análise foram concluídas a partir das falas dos participantes de equipes diferentes que se mostraram enfáticas e repetitivas sobre problemas comuns ocorridos repetitivamente no domicílio do paciente acamado.

O referencial de análise utilizado para chegar às categorias foi o de Pesquisa Convergente Assistencial (PCA). Neste estudo, a dualidade é observada quando o pesquisador se insere no serviço, na qual será realizada a pesquisa e, partindo dessa vivência, poderá investigar e propor uma nova forma de prática assistencial com a obtenção da melhoria do serviço. Assemelha-se a outras pesquisas, pois segue o passo a passo de o pesquisador perguntar-se o que pesquisar, para que pesquisar, por que pesquisar, com que suporte teórico, onde, com quem, com quais instrumentos, como e quais os resultados esperados ${ }^{(11)}$.

Quadro 1 - Divisão das Categorias.

\section{CATEGORIAS UNIDADE DE SIGNIFICAÇÃO (INDICADORES)}

1. Cuidados

no ambiente domiciliar

- Conceituar / aceitar as competências por parte do profissional e familiares.

- Atentar-se às necessidades básicas do paciente acamado.

- Atentar às necessidades do domicilio para melhoria da segurança

2. Riscos no ambiente domiciliar

\section{Educação Per-} manente: estratégia para melhoria da assistência ao paciente acamado no domicílio do paciente.

- Avaliar os riscos potenciais no domicilio.

- Conscientizar o paciente e familiares dos potenciais risco no domicílio.

\section{- Conscientizar a equipe no fazer e conduzir a assistência ao paciente acamado dentro do conhecimento técnico científico}


As categorias de análise foram evidenciadas pela fala dos participantes que se repetiam em questões relativas a cuidados diários com o paciente e a riscos expostos no domicílio por falta de orientação. Já em relação ao agrupamento das unidades de significados, este foi elaborado para atender as necessidades dos resultados referentes às categorias criadas.

Quadro 2 - Quadro dos diagnósticos de enfermagem relacionados com as necessidades humanas básicas e com a segurança do paciente. Rio de Janeiro, RJ, 2019.

\begin{tabular}{|c|c|c|}
\hline $\begin{array}{l}\text { Diagnóstico de } \\
\text { Enfermagem }\end{array}$ & $\begin{array}{l}\text { Segurança do } \\
\text { Paciente }\end{array}$ & $\begin{array}{l}\text { Necessidades } \\
\text { Humanas Básicas }\end{array}$ \\
\hline $\begin{array}{l}\text { Conhecimento } \\
\text { sobre medidas } \\
\text { de segurança }\end{array}$ & $\begin{array}{l}\text { Identificação } \\
\text { do paciente }\end{array}$ & $\begin{array}{l}\text { - Segurança emocional } \\
\text { - Comunicação } \\
\text { - Autoimagem } \\
\text { - Atenção }\end{array}$ \\
\hline $\begin{array}{l}\text { Falta de apoio } \\
\text { familiar }\end{array}$ & $\begin{array}{l}\text { Comunicação } \\
\text { efetiva }\end{array}$ & $\begin{array}{l}\text { - Educação para a saúde/ } \\
\text { aprendizagem } \\
\text { - Liberdade e } \\
\text { participação } \\
\text { - Comunicação } \\
\text { - Autoestima, autocon- } \\
\text { fiança, autorrespeito }\end{array}$ \\
\hline $\begin{array}{l}\text { Adesão ao } \\
\text { regime medica- } \\
\text { mentoso }\end{array}$ & $\begin{array}{l}\text { Prescrição } \\
\text { segura }\end{array}$ & $\begin{array}{l}\text { - Educação para a saúde/ } \\
\text { aprendizagem } \\
\text { • Comunicação }\end{array}$ \\
\hline $\begin{array}{l}\text { Reação medica- } \\
\text { mentosa }\end{array}$ & $\begin{array}{l}\text { Administra- } \\
\text { ção de me- } \\
\text { dicamentos } \\
\text { segura }\end{array}$ & $\begin{array}{l}\text { - Segurança física/meio } \\
\text { ambiente } \\
\text { - Terapêutica } \\
\text { - Educação para a } \\
\text { saúde/ aprendizagem }\end{array}$ \\
\hline $\begin{array}{l}\text { Risco de } \\
\text { infecção }\end{array}$ & $\begin{array}{l}\text { Cirurgia segu- } \\
\text { ra }\end{array}$ & $\begin{array}{l}\text { - Segurança física/meio } \\
\text { ambiente } \\
\text { - Terapêutica } \\
\text { - Educação para a } \\
\text { saúde/ aprendizagem } \\
\text { - Segurança emocional }\end{array}$ \\
\hline $\begin{array}{l}\text { Capacidade } \\
\text { de executar a } \\
\text { higiene } \\
\text { prejudicada }\end{array}$ & $\begin{array}{l}\text { Higienização } \\
\text { das mãos }\end{array}$ & - Segurança física \\
\hline Risco de queda & $\begin{array}{l}\text { Prevenção de } \\
\text { queda }\end{array}$ & $\begin{array}{l}\text { - Percepção dos órgãos } \\
\text { dos sentidos } \\
\text { - Segurança física/meio } \\
\text { ambiente } \\
\text { - Alimentação } \\
\text { - Integridade física }\end{array}$ \\
\hline $\begin{array}{l}\text { Risco de lesão } \\
\text { por pressão }\end{array}$ & $\begin{array}{l}\text { Prevenção } \\
\text { de lesão por } \\
\text { pressão }\end{array}$ & $\begin{array}{l}\text { - Hidratação } \\
\text { - Alimentação } \\
\text { - Oxigenação } \\
\text { - Integridade física } \\
\text { - Exercícios físicos }\end{array}$ \\
\hline
\end{tabular}

\section{1a Categoria: Indicadores de Cuidados no Ambiente Domiciliar}

Está categoria, reforça que o ambiente domiciliar é importante para manutenção da saúde do indivíduo e o processo do cuidar de forma holística. O enfermeiro possui habilidades e competências para oferecer uma assistência domiciliar de qualidade, trazendo o paciente como percussor do seu cuidado e a família como participante deste processo. Sobre essa visão, uma participante do estudo vem corroborar:

“..A partir do momento que eu entro no portão, eu já olho ao redor. Tem mato? Tem pneu? Tem caixa d'água? Porque principalmente agora que a gente está em época de verão, em época de dengue, Chikungunya. Então, eu já vou entrando e já vou olhando, eu olho, reparo. Entro na casa da pessoa, aí vejo a situação do paciente. É acamado? Se é acamado, vamos olhar o colchão. Se o colchão é apropriado, se o lençol está esticadinho, porque não adianta nada o colchão ser apropriado e a cama não está esticadinha." (Equipe Sul América)

Observa-se um movimento de refletir sobre a própria prática no depoimento da participante, à medida que ela se sente responsável pelo entorno do cuidado domiciliar. Donald Schön ${ }^{(12)}$, valoriza a reflexão na ação - o pensar o que fazem, enquanto o fazem. Toda ação tem um propósito, uma finalidade. Não deve apenas ser algo mecanicista sem reflexão de quais benefícios a ação pode gerar no bem-estar do indivíduo naquele momento.

Wanda Horta(9) valoriza dentro do contexto das necessidades humanas básicas, a hidratação, alimentação, integridade física e o cuidado corporal como alguns pontos importantes para prevenção de lesões por pressão. Essa reflexão na ação, nos cuidados com o paciente acamado, nos faz correlacionar as ações da Sistematização da Assistência que proporcionará o bem-estar físico do indivíduo, o que é determinante para suas condições de saúde.

Segundo Vieira, Bezerra, Sobreira, Silva e Feitosa(13), os profissionais de saúde da familia, com enfoque na equipe de enfermagem, quando acompanha o paciente acamado no domicilio, altera direta ou indiretamente a rotina da família, a partir, dos cuidados oferecidos ao paciente. É importante frisar que de acordo com mesmos autores ${ }^{(14: 1)}$ : "Entende-se como paciente acamado aquele que se encontra impossibilitado de exercer o autocuidado de forma parcial ou total, necessitando de auxilio".

Wanda Horta ${ }^{(9)}$, dentro de suas teorias, enfatiza a importância da prevenção dos riscos de queda que está relacionado com a segurança física dentro do espaço, do ambiente; pois essa prevenção de queda em um ambiente 
domiciliar é extremamente importante em consequência de muitos pacientes possuírem um déficit de regulação neurológica.

Segundo Pires, Rodrigues e Nascimento(14), a integralidade do cuidado aparece como complexo, inovador e com diversos sentidos que, de certo modo, associam às necessidades verbalizadas pelos usuários do sistema e suas famílias, vinculado a prática dos trabalhadores de saúde, visando a resolubilidade das questões apresentadas pela clientela, face ao cuidado integral. A abertura ao diálogo, entre os participantes deste processo, e a aplicabilidade das variadas formas de agir em saúde, para atender as demandas relacionadas às ações entre o indivíduo/família/grupos populacionais.

O cuidado no ambiente domiciliar visa atender, seja de forma total ou parcial, as demandas do paciente. A consciência da família em relação a essas demandas é extremamente importância para melhoria de sua terapêutica, pois nada pode ser feito de forma isolada, em relação às necessidades do mesmo. A equipe de saúde da família, precisa estar em conformidade com a família, para contribuir para a melhoria da qualidade de vida do indivíduo de forma integralizada.

O paciente domiciliar acamado quando entende a sua condição e tenta promover o seu autocuidado mesmo de forma limitada, melhora a sua condição no âmbito domiciliar. Usa-se estratégias por parte dos profissionais de enfermagem juntamente com os agentes comunitários de saúde, para adesão ao tratamento de forma adequada, seja no uso de medicações como em outras necessidades do usuário. A enfermeira da unidade faz um breve relato em relação ao uso de medicações para atender as necessidades do paciente:

“...Em relação às medicações, eu acho muito válido essa questão de você fazer o esquema mesmo de desenho ou de cor e tudo o mais, mas nem toda a familia aceita..." (Equipe Cinco Bocas)

“...Eu falei "Rafa, vamos dar um jeito" ai ele não tinha muitas condições, mas não interessa. Eu fui na farmácia e peguei uma caixa de qualquer remédio que tinha acabado, cortei, fiz uma divisória e falei "Rafa, olha só, fala para ele que esse remédio que está aqui onde tem a fita é da manhã, o outro é o que ele tem que tomar pela manhã e à noite" funcionou muito bem..." (Equipe Cinco Bocas)

Segundo Schön ${ }^{(12)}$, quando um profissional visualiza um problema, ele define que forma irá resolver o mesmo e que estratégias irá utilizar para alcançar os impactos na prática. O profissional precisa entender qual é a sua responsabilidade na ação, suas metas, e que estratégias precisam delimitar para gerar impacto na ação com a reflexão na prática. Os conhecimentos técnicos e científicos adquiridos ao longo da graduação influenciam nas tomadas de decisões frente a assistência, desenvolvendo uma postura crítica e reflexiva diante das situações problemas de modo a desenvolver condutas que geram resultados na ação e reflexão da prática assistencial.

Enquanto Wanda Horta ${ }^{(9)}$, em sua teoria psicobiológica, no contexto terapêutico, correlaciona a importância da segurança física para estabelecer uma condição assertiva, promovendo a educação para a saúde do usuário, em relação a administração dos medicamentos e trabalhar o processo de aprendizagem em relação a orientações estabelecidas pelos profissionais de saúde para o usuário e familiares.

\section{2a Categoria: Indicação dos Riscos no Ambiente Domiciliar}

O conceito de saúde orienta as práticas de cuidados de cada indivíduo e se correlaciona aos acontecimentos socioeconômico-políticos-culturais, consequentemente, com diferenças ao longo do tempo. Por tal motivo, a importância de entender quais os pensamentos de populações específicas que norteiam o cuidar de sua própria saúde, pois quando não se entende claramente estas práticas, gera-se riscos no ambiente domiciliar.

Sobre este aspecto, o participante da entrevista exprime o seu pensamento em relação a indicação dos riscos:

“...A gente chegou a orientar a familia sobre a troca do colchão, que ela dormia. Ela não dormia, ela ficava no sofá direto na sala. Então a gente orientou sobre a troca do colchão para colocar um acolchoado - aquele casca de ovo - para ter como a pele respirar.... (Equipe Sainá)

De acordo com Schön ${ }^{(12)}$, não é através de soluções técnicas para os problemas que convertemos situações problemáticas em problemas bem definidos; ao contrário, é através da designação e da concepção que a solução técnica de problemas que se torna-se possivel.

$\mathrm{Na}$ prevenção de lesões por pressão, Wanda Horta ${ }^{(9)}$ na percepção dos órgãos e sentidos, uns dos focos das necessidades psicobiológicas, afirma que a valorização da alimentação, hidratação e oxigenação podem melhorar a pele do paciente. Esse pensamento vai ao encontro da visão dos autores Gandolfi, Siega, Rostirolla, Kleba e Colliselli(15:3695) "sobre a melhoria das práticas assistenciais: Nesse sentido, a Sistematização da Assistência de Enfermagem (SAE) constitui-se como ferramenta importante, em especial no desenvolvimento de cuidados aos pacientes com maiores necessidades. A realização da SAE revela compromisso com a melhoria da qualidade da assistência prestada ao paciente, enriquecendo a prática dos enfermeiros e elevando 
o desempenho profissional nesse processo. Possibilita, ainda, ao enfermeiro fortalecer sua autonomia, delimitando a essência de sua prática profissional".

Outra participante se mantém na mesma linha de cuidado descrita acima:

“...Esse sofá não era aconselhado por quê? Qualquer movimento que ela desse, ela não tinha segurança. Ela tinha a segurança das costas do sofá, mas na frente não tinha nenhuma..." (Equipe Sainá)

Muitos riscos no ambiente domiciliar são provenientes da falta de informação por parte dos profissionais de saúde em orientar os pacientes e familiares na melhoria do conforto e da segurança do paciente. Existem metas que precisam ser vistas de forma muito criteriosa para não gerar riscos e maiores danos. Uma participante do estudo relata a questão:

“... a pessoa é hipertensa e a gente chega lá às vezes umas 10h da manhã, umas llh e familia ainda não fez essa medicação no paciente. Assim, ela é hipertensa e ela tomou a medicação dela. O paciente que está lá. O familiar. Não tomou a medicação. Aí a gente chega "não tomou a medicação? Por que não tomou a medicação?..."

(Equipe Sul América)

Seguindo o estudo de Gomes, Salvador, Rodrigues, Silva, Ferreira e Santos(16:147): "Os eventos adversos (EA) são incidentes passiveis de ocorrer durante a prestação do cuidado à saúde e que resultam em dano ao paciente, os quais podem ser de natureza física, social e/ou psicológica, o que inclui doença, lesão, sofrimento, incapacidade ou morte".

A segurança do paciente visa proporcionar métodos que não causem danos ou riscos que possam levar o indivíduo a morte. Aequipe de saúde da família tem como objetivo orientar o indivíduo e os familiares nesses riscos, desde a forma correta de manipulação e administração de medicamentos, para reduzir os riscos no domicílio.

Sobre o risco de queda, uma participante relata com muita veemência em relação a este problema:

“..Ah, essa foi a dona Ana. Dona Ana também mora sozinha. Ela caiu. Caiu Ih e meia da manhã e ficou até $8 \mathrm{~h}$ da manhã pedindo socorro. Um senhor que passou na rua escutou ela gritando e perguntou - "o que que está havendo?" e ela - "pelo amor de Deus, me socorre! Me socorre!" ele foi e entrou, chamaram a SAMU, levaram ela.... (Equipe Minuanos)

A Segurança do paciente precisa ser vista com relevância para redução dos riscos e danos desnecessários associados à assistência no domicílio. Em saúde, nenhum risco deve ser aceito relacionado a segurança do paciente, visando que seja em qualquer aspecto, existem formas evitáveis para minimização ou redução do mesmo.

Foi construído um mapa conceitual, a partir dos problemas mais comuns ocorridos no domicílio pela fala dos participantes. Pode-se observar que existe necessidade de orientação por partes dos profissionais em algumas situações, e também existem algumas mistificações em determinadas condutas em relação a saúde do paciente, por parte da família.

Figura 1 - Mapa conceitual da análise dos dados. Rio de Janeiro, RJ, 2018.

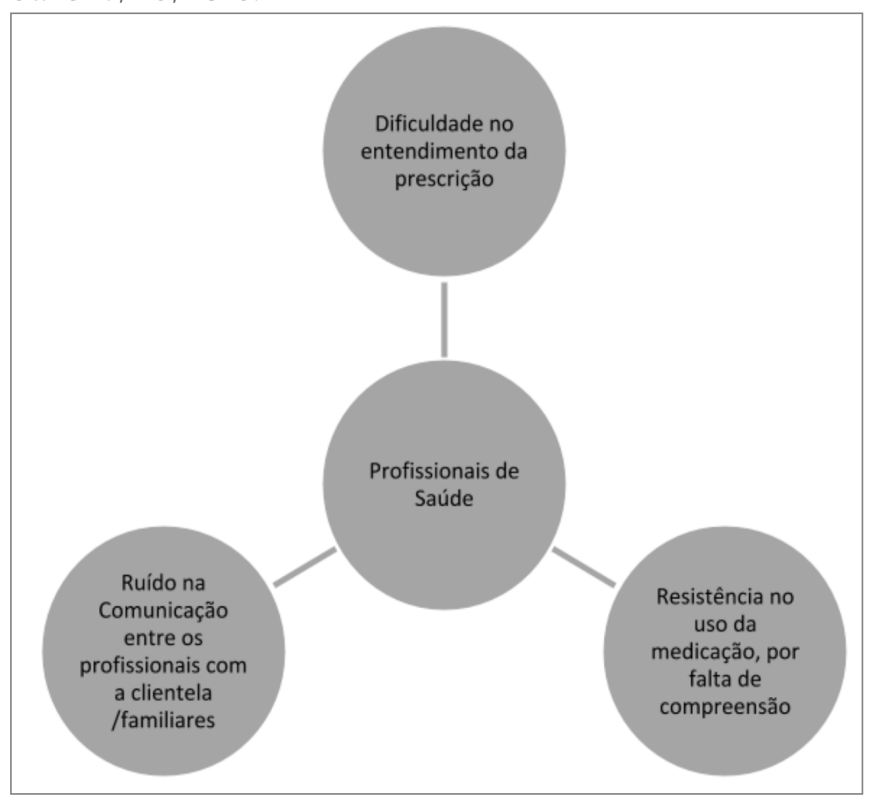

\section{DISCUSSÃO}

Existem fatores que estão relacionados ao estado de saúde das pessoas, tais como: o nível de desenvolvimento social e econômico do país, a infraestrutura existente, as condições de saneamento básico, de moradia e de trabalho; a afetividade, a sexualidade e a diversidade cultural; o grau de desigualdade de renda, entre outros, afetam o processo de saúde e doença.

A família junto a equipe de saúde precisa estar conectada em todos os processos; entender que a terapêutica não está somente voltada para o tratamento medicamentoso, que as simples ações do cotidiano, como o padrão alimentar, a hidratação, a higiene, a integridade física, até o laços afetivos, como o amor, são fundamentais para se ter uma melhor condição de vida. Esses processos sistematizados pelo enfermeiro e orientados pela equipe de saúde são importantes e desafiadores A educação deve ser valorizada como um trabalho de coletividade e valorização das vivências de cada 
um, visando a busca constante de novos instrumentos para o trabalho. Dessa forma, a educação visa o movimento de reconstrução do conhecimento do indivíduo de forma personalizada. $O$ indivíduo para promover a educação de forma eficiente precisa de autonomia intelectual, ser transformador da realidade, pensamento crítico e reflexivo para as práticas de saúde, valorizando suas potencialidades ${ }^{(18)}$.

A Educação Permanente (EP) pode transformar no processo de trabalho baseado com repercussão na vida do usuário, na perspectiva da educação, ampliando a construção de espaços coletivos que envolvem reflexão e avaliação das ações produzidas no processo de trabalho da equipe. Propõe-se buscar métodos de uma reflexão crítica em relação às práticas de serviço com a prática educativa associada ao trabalho que desenvolve transformando os processos de trabalhos, nas atitudes, na organização, com os profissionais da equipe; possibilita a transformação do processo de organização da atenção, um cuidado mais humanizado, articulação entre as equipes visando o benefício dos usuários ${ }^{(18)}$.

A Educação Permanente constitui alternativas viáveis para mudanças no ambiente de trabalho com objetivo de desenvolver formas diferenciadas de educar e aprender, através de técnicas e treinamentos específicos estimulando a participação dos atores envolvidos no processo, com a estimulação do pensamento crítico e reflexivo. Portanto, a educação permanente visa transformar as práticas profissionais dos trabalhadores por meio de respostas construídas através de reflexões da sua própria prática(19).

Lavich, Terra, Mello, Raddatz, Arnemann(18:2), reforçam que: "A EPS foi criada e implementada como Política, em conformidade com a Constituição Federal, Portaria № 1.996, de 20 de agosto de 2007, pelo Ministério da Saúde (MS). Com isso, a EPS se tornou uma possibilidade para o enfermeiro desenvolver suas competências relacionadas à sua atuação profissional de maneira qualificada, frente a complexidade de seu trabalho".

Evidencia-se que a importância do bem-estar e da segurança do paciente acamado no domicílio foi bem reforçada e clara, como discurso de todos os participantes, e a consciência de sua função e responsabilidades em relação ao paciente. As teorias de Wanda Horta(9) e Donald Schön ${ }^{(12)}$, entrelaçaram a valorização das necessidades básicas afetadas e a importância do profissional colocar ação e reflexão na prática assistencial. O estudo realizado, apresentou informações importantes em relação a sistematizar a assistência de enfermagem através das tecnologias leves. No campo das tecnologias leves, a interação entre enfermeiros e pacientes, familiares ou cuidadores se configura como uma ação importante na atenção básica. Assim, as tecnologias leves de cuidado aparecem em ações como escuta ativa, apoio, conforto, respeito, relação de ajuda e diálogo, comunicação efetiva e no estabelecimento de uma relação de confiança com usuários e familiares, o que constitui parte fundamental do trabalho deste profissional na atenção básica.

\section{Limitações do estudo}

A limitação do estudo se deve ao fato de terem poucos estudos e publicações acerca da temática, dificultando a análise dos dados e a discussão.

\section{Contribuições do estudo para a prática}

O estudo contribui no âmbito da atenção básica elencada a Segurança do Paciente e a Sistematização da Assistência de Enfermagem, uma assistência de enfermagem qualificada, de forma segura ao paciente, com o objetivo de reduzir complicações durante o tratamento de modo a facilitar a adaptação e recuperação do paciente no âmbito domiciliar.

\section{CONSIDERAÇÕES FINAIS}

Com a pesquisa realizada, foi possível identificar problemas potenciais no domicílio do paciente acamado, como: cama inadequada, administração incorreta de medicamentos em relação a dosagem e horários, queda da própria altura de pacientes acamados; e concluir que mudançassãonecessárias deseremrealizadasparamelhoria da qualidade do serviço. Acredita-se que a aplicabilidade adequada para apresentação da educação em saúde é fundamental para o entendimento e a solidificação das informações por parte dos profissionais, com o intuito de oferecer uma assistência de qualidade no âmbito domiciliar ao paciente acamado, e estas informações precisam ser claras e concisas para facilitar as melhores condições de assistência a esse grupo. A equipe multidisciplinar tem papel fundamental neste processo, pois a assistência ao paciente deve ser realizada de forma holística. Todos os profissionais precisam se correlacionarem em busca de melhores condições de saúde do indivíduo.

Contribuição dos autores: Concepção e/ou desenho: "Autor 1"; Análise e interpretação dos dados: "Autor 1", "Autor 2"; Redação do texto: "Autor 1"; Revisão crítica: "Autor 1", "Autor 2"; Revisão final: "Autor 2". 


\section{REFERÊNCIAS}

1. Ministério da Saúde (BR). Programa Nacional de Segurança do Paciente. Portaria no 529, de 1으 de Abril de 2013. Institui o Programa Nacional de Segurança do Paciente (PNSP). [cited 2017 Nov. 20]. Available from: http://bvsms.saude.gov.br/bvs/ saudelegis/gm/2013/prt0529_01_04_2013.html

2. Ministério da Saúde (BR). Programa Nacional de Segurança do Paciente. Brasilia: Ministério da Saúde, 2013. [cited 2017 Oct 05]. Available from: http://www.saude.gov.br/acoes-e-programas/programa-nacional-de-seguranca-do-paciente-pnsp

3. Agência Nacional de Vigilância Sanitária (ANVISA). Resolução de Diretoria Colegiada-RDC no 36, de 25 de julho de 2013. Institui ações para a segurança do paciente em serviços de saúde e dá outras providências. [cited 2017 Nov 12]. Available from: http://portal.anvisa.gov.br/documents/10181/2871504/RDC_36_2013_COMP.pdf/36d809a4-e5ed-4835-a375-3b3e93d74d5e

4. Ministério da Saúde (BR). Portaria MS/GM nㅇ 2.527 de 27 de outubro de 2011. Redefine a atenção domiciliar no âmbito do Sistema Único de Saúde (SUS). Disponivel em: <http://bvsms.saude.gov.br/bvs/saudelegis/ $\mathrm{gm} / 2011 /$ prt2527_27_10_2011_comp.html>. Acesso em: 12 ago. 2019.

5. Ministério da Saúde (BR). Resolução de Diretoria Colegiada - DC no 36, de 25 de julho de 2013. Institui ações para a segurança do paciente em serviços de saúde e dá outras providências. Brasília, DF, 2013. Disponivel em: <http://portal. anvisa.gov.br/documents/10181/2871504/RDC_36_2013_ COMP.pdf/36d809a4-e5ed-4835-a375-3b3e93d74d5e>. Acesso em: 09 nov. 2017.

6. Prefeitura do Rio de Janeiro 2010. Programa de Atenção Domiciliar ao Idoso - PADI. 2010. Disponivel em: <http:// www.rio.rj.gov.br/web/sms/padi>. Acesso em: 15 ago. 2019.

7. Silva EGC, Oliveira VC, Neves GBC, Guimarães TMR. O conhecimento do Enfermeiro sobre a Sistematização da Assistência de Enfermagem: da teoria à prática. Revista da Escola de Enfermagem da USP [Internet]. 2011 [cited 2018 Set 12]; 45(6):1380-1386. Available from: http://www.scielo.br/pdf/ reeusp/v45n6/v45n6al5.pdf

8. Chaves LD, Solai CA. Sistematização da Assistência de Enfermagem: considerações teóricas e aplicabilidade. 2. ed. São Paulo: Martinari, 2013

9. Horta WA. Processo de Enfermagem. Rio de Janeiro: Guanabara Koogan; 2011.

10. Conselho Nacional de Saúde (BR). Resolução nํ 466, de 12 de dezembro de 2012. Diretrizes e normas regulamentadoras de pesquisas envolvendo seres humanos. Brasilia, 2012. [cited 2018 Out 10]. Available from: http://bvsms.saude.gov. br/bvs/saudelegis/cns/2013/res0466_12_12_2012.html
11. Trentini M, Paim L. Pesquisa em enfermagem: um desenho que une o fazer e o pensar na prática assistencial de saúde-enfermagem. 2. ed. Florianópolis: Insular, 2004

12. Schön DA. Educando o profissional reflexivo: um novo design para o ensino e a aprendizagem. Artmed: Porto Alegre; 2000.

13. Vieira HF, Bezerra ALD, Sobreira MVS, Silva JB, Feitosa ANA. Assistência de enfermagem ao paciente acamado em domicilio: uma revisão sistemática. FIEP Bulletin [Internet]. 2015 [cited 2018 Jun 03]; 85(II):478-486. Available from: http://www.fiepbulletin.net/index.php/fiepbulletin/article/ view/85.22.60/10671

14. Pires VMMM, Rodrigues VP, Nascimento MAA. Sentidos da integralidade do cuidado na saúde da familia. Revista Enfermagem UERJ [Internet]. 2010 [cited 2018 Jun 03];18(4):622-627. Available from: http://www.facenf.uer.j.br/ v18n4/v18n4a20.pdf

15. Gandolfi M, Siega CK, Rostirolla LM, Kleba ME, Colliselli L. Sistematização da Assistência de Enfermagem: da teoria ao cuidado integral. Revista de Enfermagem UFPE [Internet]. 2016 [cited 2018 Set 02]; 10(Supl. 4):3694-3703. Available from: https://periodicos.ufpe.br/revistas/revistaenfermagem/article/download/11146/12653

16. Gomes ATS, Salvador PTCO, Rodrigues CCFM, Silva MF, Ferreira LL, Santos VEP. A segurança do paciente nos caminhos percorridos pela enfermagem brasileira. Revista Brasileira de Enfermagem [Internet]. 2017 [cited 2017 Aug 15]; 70(1):146-154. Available from: http://www.scielo.br/pdf/ reben/v70nl/0034-7167-reben-70-01-0146.pdf

17. Azevedo IC, Silva GWS, Vale SL, Santos QG, Cassiano NA, Moraes IF et al. Educação continuada em enfermagem no âmbito da educação permanente em saúde: revisão integrativa de literatura. Revista Saúde e Pesquisa [Internet]. 2015 [cited 2017 Out 10]; 8(1):131-140. Available from: http:// periodicos.unicesumar.edu.br/index.php/saudpesq/article/ view/3275

18. Lavich CRP, Terra MG, Mello AL, Raddatz M, Arnemann CT. Ações de educação permanente dos enfermeiros facilitadores de um núcleo de educação em enfermagem. Revista Gaúcha de Enfermagem [Internet]. 2017 [cited 2017 Ago 08]; 38(1):e62261. Available from: http://www.scielo.br/pdf/ rgenf/v38nl/0102-6933-rgenf-1983-144720170162261.pdf

19. Sardinha LP, Gonçalves LC, Dutra TC, Tavares CMM, Dantas ACC, Cortez EA. Educación permanente, continuada y de servicio: desvelando sus conceptos. Revista Enfermería Global [Internet]. 2013 [cited 2018 Nov 04]; 12(29):307-322. Available from: http://scielo.isciii.es/scielo.php?script=sci_arttextEpid=S1695-61412013000100017 